\title{
Assessing Knowledge and Preventive Behavior of BC Hikers Towards Lyme Disease
}

\author{
Goodarz Nategh ${ }^{1}$, Dale Chen ${ }^{2}$
}

1 Lead Author, B. Tech Student, School of Health Sciences, British Columbia Institute of Technology, 3700 Willingdon Ave, Burnaby BC, V6G 3H2

2 Supervisor, School of Health Sciences, British Columbia Institute of Technology, 3700 Willingdon Ave, Burnaby BC, V6G 3H2

\section{Abstract \\ Background}

In Canada, recent data shows that Lyme diseases (LD) have increased in many different regions of the country. British Columbia $(\mathrm{BC})$, with its natural beauty and suitable terrain for outdoor activities, has drawn thousands of hikers to the established hiking trails, as well as off-trail wilderness. Consequently, more people are expected to be exposed to Lyme disease every year. For better understanding of the risk, study of their knowledge and awareness, and also their preventative behavior against Lyme disease is necessary. The purpose of our study is to evaluate hiker awareness about LD and assess type and frequency of preventive measures they take against the disease.

\section{Methods}

A self-administered electronic survey was created and disseminated online among hikers in British Columbia, Canada. The online survey distributed via the social platform, Reddit, and took approximately five minutes to complete. The results were collected and organized in Microsoft Excel and analyzed with NCSS statistical software (NCSS, 2021).

\section{Results}

The results of this study indicated that general awareness of LD among hikers in British Columbia is high. Ninety-eight percent of participants in the study have heard about the LD before the study was conducted. Hikers are generally aware of the prevalence of the disease $(83 \%)$ in $\mathrm{BC}$ and know that ticks are problematic for them (74\%). Majority of hikers $(92 \%)$ have taken at least one measure to protect themselves against the disease. Avoiding tall grasses and bushwalking while hiking was the most popular method as $46 \%$ of the hikers frequently (more than half the time) took this measure. In contrast, wearing protective cloths or tucking pants into socks were the least frequent methods taken by them. Also, $68 \%$ of the hikers never used chemical insect repellent to deter ticks. This result suggests that avoiding 
ticks and tick bites by avoiding grassy areas, where ticks might be present, is the preferred method over the usage of chemical insect repellants, or physical barriers against tick bites such as wearing protective cloths or tucking pants into the socks; however, further data is needed to precisely conclude this result.

Our study found that there are no significant statistical associations between hiker's knowledge and their level of education $(\mathrm{P}=0.77)$, hiker's education level and preventive method taken $(\mathrm{P}=0.91)$, level of hiking experience and preventive method taken $(\mathrm{P}=0.86)$ or gender of the hikers and preventive methods taken $(\mathrm{P}=0.068)$ against the Lyme disease.

\section{Conclusions}

As Lyme disease has been recognized as a potentially increasing infectious disease in British Columbia, assessment of hiker's knowledge and preventive behavior towards LD through an online survey concluded that BC hikers have high level of awareness about the disease, and they protect themselves against the tick bites.

As predictive models show that climate change and warmer weather cause an expansion in tick habitat in North America, probability of hikers being exposed to ticks is higher. As the risk increases, LD prevention campaigns could be designed considering what prevention methods are the most popular; and more effective or innovative prevention methods could be introduced to the population. Health authorities may introduce LD prevention initiatives and educational plans that are adaptable and suitable to the geographical region based on prevalence of the disease. Similarly hiking groups may educate their new members regarding the disease, how to prevent it and what methods are suitable based on the region they are active in.

\section{Keywords}

British Columbia, Hiking, Lyme disease, Tick bite, Ixodes pacificus, Outdoor activity 


\section{Introduction}

In Canada, recent data shows that Lyme diseases have increased in many different regions of the country. According to Public Health Agency of Canada (PHAC), reports from all Canadian provinces show that Lyme disease cases increased from 144 in 2009 to 992 in 2016 (Public Health Agency of Canada, 2018). The number of cases had been increasing steadily till 2011 but after Lyme disease became a notifiable disease in 2009 , the number of human cases increased relatively sharply (PHAC, 2018).

There has been number of studies that assessed, evaluated and monitored the vector-borne diseases and their public health impacts. Surveillances and studies as such have helped decision makers, the public and other stakeholders to understand the needs, the limitations, the possibilities and the challenges ahead. It is imperative that continuation of similar studies, particularly in a population at a higher risk, provides accurate data to stakeholders and public health professionals.

British Columbia, with its natural beauty and suitable terrain for outdoor activities, has drawn thousands of people to the established hiking trails, as well as off trail wilderness. And consequently, a larger number of people are expected to be exposed to tick-borne diseases such as Lyme disease every year. For better understanding of the risk to the population, studying the knowledge of hikers in BC, and their preventative behavior is a necessary step. So far, there have not been studies that seek to assess the hiking population's knowledge and their preventative behavior regarding Lyme disease. Since B.C. has a considerable population of hikers, such study will help to fill the scientific gap in the subject matter.

\section{Literature Review}

Both West Nile virus and Lyme disease have emerged as a public health concerns in many parts of Canada (Lindsay et al., 2015). More significant than West Nile virus, Lyme disease prevalence increased between 2009-2018 (Health Canada, 2019). "The number of reported Lyme disease cases increased more than six-fold, from 144 in 2009 to 917 in 2015, mainly due to an increase in infections acquired in Canada"(Koffi \& Gasmi, 2019).

\section{What is Lyme Disease?}

Lyme Disease (LD) is a well-known tick-borne illness which is caused by the bacteria Borrelia burgdorferi. The 
symptoms include fever, headache, joint and muscle pain, and swollen lymph nodes. There are two types of ticks that can spread Lyme disease in Canada. Blacklegged tick (Ixodes scapularis) in southeastern and south-central regions of Canada and western blacklegged tick (Ixodes pacificus) in British Columbia (Public Health Agency of Canada, n.d.). Since ticks need blood to survive and reproduce, they attach on wild animals and humans to feed. Borrelia burgdorferi enters ticks while they are feeding from infected wild animals. Once ticks are infected, they spread the bacteria through their bites to humans and other animals like pets (Public Health Agency of Canada, n.d.). Ticks attach to different part of the body, more often to hard-to-see spots such as sculp, armpit and the groin. And they should remain attached to the skin, in most cases 36-48 hours, till the Lyme agent can be transmitted from them to the human or pet (CDC, 2020).

Lyme disease if left untreated, it causes serious health problems to humans (Halperin, 2015). Signs and symptoms of Lyme disease could start as early as 3 days to 30 days after people get exposed ((Public Health Agency of Canada, 2018). Most people experience flu-like symptoms soon after being bitten. A small number may have more serious symptoms. Rash, red shaped like a bull's eye, fever, headache, chills, fatigue, muscle/ joint pain and swollen lymph nodes are the early symptoms of the disease (Public Health Agency of Canada, 2018).

\section{Is Lyme Disease Serious?}

If people are left untreated, more severe symptoms may occur and can last for a long time. Severe headaches, Facial paralysis, severe muscle, joint, tendon and bone aches, heart disorders, and neurological disorders as well as arthritis with severe joint pain and swelling are severe symptoms that may occur (Public Health Agency of Canada, 2018). Lyme disease can lead to complications involving infection of the heart which causes death in rare cases (Public Health Agency of Canada, 2018). In 10-15\% of untreated patients nervous system will be involved (Halperin, 2015).

\section{Lyme Disease Prevention}

Lyme disease is preventable if people wear appropriate clothing and use $\mathrm{N}$, $\mathrm{N}$-diethyl-meta-toluamide

(DEET) repellents (Ogden et al., 2009). Repellant such as DEET would prevent tick bite by deterring the tick from the skin (Ogden et al., 2009). Other preventive measures can also be taken to reduce the risk of tick bite (Due et al., 2013). Health Canada has listed 
number of ways that one can protect himself/herself from the tick bite. Wearing light-colored long-sleeved shirts and pants to spot ticks more easily, tucking your shirt into your pants, and pull your socks over your pants legs, walking on cleared paths or walkways and taking shower or bath within two hours of being outdoor, checking for tick on your skin and doing a full body check particularly in the hair, under the arms, in and around the ears, inside the belly button, behind the knees, between the legs and around the waist (Public Health Agency of Canada, n.d.).

Removing the tick within 24-36 hours can help prevent infection. Doing a tick check on your outdoor gear and your pets as they could carry ticks inside your home is necessary. Ensuring that your clothing is free of ticks by Putting outdoor clothes in a dryer on high heat for 10 minutes to kill any remaining ticks (Public Health Agency of Canada, n.d.).

\section{Lyme Disease in BC}

According to BCCDC's annual summaries of reportable diseases, there were 160 lab-confirmed cases of Lyme disease between 2008 and 2017 in BC. Since 2009 there was an upward trend in Lyme disease with a peak of 40 cases in 2016 (BCCDC, 2020). That said, according to a study conducted in 2018 in Canada
(Lloyd \& Hawkins, 2018), Lyme disease cases are underreported due to conservative approach to testing in order to exclude false positive results. In consequence of this approach false negatives result in underestimation of Lyme disease cases in Canada (Lloyd \& Hawkins, 2018). Although BC does not have a large number of cases and is a rare disease at the time, there is a chance of underreported cases throughout province (Henry et al., 2011).

Another important aspect is the emergence of Lyme disease in areas where the disease is not endemic due to the climate change. Predicting models regarding the effect of climate change on Lyme disease suggests that ticks' habitat and their area of activity will be expanded in the near future in North America (Brownstein et al., 2005). Extrapolations of the data from climate change scenarios, the study predicted significant expansion in ticks activity and their habitat in North America. (Brownstein et al., 2005). At the time in which study was conducted, the results predicted with high accuracy $(89 \%$ $\& \mathrm{P}<0.0001$ ), that tick's suitable habitat will be expanded into Canada by $213 \%$ in 2080(Brownstein et al., 2005). This expansion of suitable habitat may result in their population growth and their need of food. That increases the probability of tick bites in outdoor users including hikers. 


\section{Lyme Disease and Its Relevance to Hikers}

Lyme disease as one representative of the vector-borne diseases, is the most prevalent in North America (Mead, 2015) and is the most relevant to the hiking population. According to the US Centre for Disease Control (CDC), hikers are at risk for Lyme disease since they are exposed to the environment, wooded area and brushes, they are more likely to come in contact with ticks, carrier of the disease agent (CDC, 2020). As prevalence of diseases such as West Nile disease (no case in 2018) and Q fever ( 3 cases in 2018) are low in British Columbia (BCCDC, 2020), studying them might not represent the actual risk of vector-borne diseases to hikers. Therefore, it is important to focus on Lyme disease and the studies that look into LD and examine different populations in different outdoor activities and find similarities with hiking population. That is the main reason this paper is focused on Lyme disease as the relevant disease.

Several studies have been conducted that monitored Lyme disease by its geographical distribution in Canada. A study, Surveillance for Lyme disease in Canada: 2009-2015, showed almost ninefold increase in Lyme disease cases in Ontario between 2009 and 2015 (Koffi \& Gasmi, 2019). The study also showed that upward trends of Lyme disease, in some provinces is much more significant than other part of the country. The authors have emphasized that the number of cases increased in Manitoba and the provinces eastward. At the same time, incidences in B.C. also increased from 10 cases in 2009 to 40 cases in 2016 (BCCDC, 2020).

How populations protect themselves against the disease and what is their level of knowledge are somewhat critical questions that primarily has been answered by some research studies in a particular population. A study conducted in Delaware showed that overall participants in the study has a poor knowledge about Lyme disease. Only $38.4 \%$ of the respondent stated that ticks are problematic in Delaware while Delaware has one of the highest rate of the Lyme disease in the United States (Gupta et al., 2018). The study showed that only $12.7 \%$ of participants "strongly agreed" that the Lyme disease was an issue (Gupta et al., 2018). Among 1755 participants, more than $61 \%$ did not know that ticks are problematic. Hence, the authors concluded that overall, the knowledge of the participants regarding Lyme disease was poor. In comparison, one study conducted in Canada, mainly concentrated on eastern provinces and Atlantic Canada, showed that only $12 \%$ of the respondents had not heard 
of Lyme disease at all. Among the rest of the participants, who were aware of Lyme disease, less than $50 \%$ adopted some sort of preventative measures into their behavior towards the tick bites (Aenishaenslin et al., 2017). How do people in Canada protect themself and what is their level of knowledge? These questions will be answered by searching inside the studies which are closely related and very similar to the subject.

An article was published in International Journal of Environmental Research and Public Health, focused on outdoor users' knowledge about Lyme disease. The researchers analyzed the data from occupational and recreational outdoor users. The knowledge of two populations in Canada, who are frequently exposed to the Lyme disease was Analyzed. Their study showed that $64 \%$ of their participants were recreational users of the outdoors. Conducting a survey, authors concluded that overall, the level of knowledge about the disease and preventive methods is low. The authors also concluded that "wearing long pants and protective footwear" was the most frequently performed protective behaviors among the participants in the study (St. Pierre et al., 2020). High level of participants $(64 \%)$ were recreational outdoor users, which hikers are included but not specified, shows that the knowledge level of hikers could be low although was not directly claimed in the study. The authors' finding emphasizes that there is a need of knowledge assessment in the population (St. Pierre et al., 2020).

\section{Public Health Significance}

This study has two main public health applications. First, it will provide insight to public health authorities regarding the level of hikers' awareness and their preferred preventive behavior. This insight helps to direct the resources and appropriately allocate them. A study conducted in 2016 showed that awareness of Lyme disease in Canada significantly increased after the launch of a "national communication" campaign about the Lyme disease (Aenishaenslin et al., 2016). Whether it is the education, prevention or treatment, the resource allocation effects public health in British Columbian. Second, this study will provide in-depth information to hiking communities about their population's knowledge which helps them to improve their awareness about the risk. It is also help them to adopt preventive measures that are more compatible with their community culture or regional necessities.

Several studies showed the importance of the disease knowledge 
assessment and its effect on decisionmaking process in a specific population. A cross-sectional study conducted in 2015 discussed the factors associated with preventative behavior in two different geographical location (Aenishaenslin et al., 2015). Switzerland, where people are exposed to endemic Lyme disease compared to Canada, where the disease is emerging. The findings were extracted by analyzing the data from a survey among 814 participants in 2012. The authors extensively studied the factors associated with "applying insect repellent", "the age groups", "the knowledge of LD" and "the level of exposure". Their results showed that social and contextual factors are important considerations to take into account when designing prevention campaigns for Lyme disease. Their findings supported the importance of knowledge assessment for public health authorities to better comprehend and screen these factors in a target population in order to be able to design campaigns, adapt strategies and implement preventive programs that are well suited to a population and to their epidemiological need (Aenishaenslin et al., 2015).

\section{Material}

A secured laptop computer, Microsoft Excel 365 and NCSS statistical software were used to complete the study and analyze the data. Survey Monkey Canada Software were utilized to design the survey.

\section{Method}

A self-administered electronic survey was created via a BCIT account on Survey Monkey Canada (http://www.surveymonkey.com). The survey link was distributed on online platform Reddit. The survey consisted of two sections. A series of questions was asked on demographic factors and hiking experience, followed by knowledge and preventive measure questions. The survey collected data regarding the awareness level of hikers about Lyme disease and information about preventive measures taken by hikers while hiking in BC. The survey also collected demographic information including age group, gender, level of education as well as self-claimed hiking experience from the population. The survey was available over a three weeklong period in January 2021. Data from the 
survey was collected from January 15 th until February 3rd, 2021.

Hikers' related sub-reddit groups as well as reddit public pages for major BC towns were the target pages to disseminate the survey link when possible. The survey link was disseminated to both sub-reddit hiking related pages, where surveys were permitted as well as reddit public pages related to a town or city. Introducing the survey link to these pages was based on two main condition. First, if the reddit page or sub-reddit is related to a city or a town with certain level of population (10,000 persons) and second, that city or town is located in areas where the risk of Lyme disease actually exists. British Columbia Center for Disease Control has published a map that shows areas with higher risk of Lyme disease presence; and this map was used in the study as a determination factor to where to disseminate the survey link. This map shows that majority of $\mathrm{BC}$ population are living in the areas where LD risk is high (Appendix D)

\section{Statical Analysis}

From a total of 123 respondents to the survey, 113 met the inclusion criteria of the study. All respondents completed the knowledge and hiking experience of the survey. the descriptive statistic breakdown is as below:

\section{Demographic}

Among all participants in this study, $50.44 \%$ were male, $47.8 \%$ were female and $1.7 \%$ preferred not to answer.

The majority of respondents were hikers $19-29$ years old $(47 \%$ of the population). $52 \%$ of which were female and $48 \%$ were male. The least responses were from age groups under 19 and over 50 years old which represents around $9 \%$ of total respondents.

It was noted that $35.4 \%$ of the respondents to the survey claimed to have university undergraduate while $16 \%$ have college or technical diploma, $13.3 \%$ have university graduate degree and $11.5 \%$ have some university education. It was also noted that $13.3 \%$ of the respondents claimed to have high school or earlier grades education. (Figure 1)

In this study, $56.5 \%$ of the respondents were experienced (5-10 years of hiking experience) or highly experienced hikers while more than half of the respondents (56 \%) spent more than 10 hours per month doing hiking. (Figure 2)

\section{Lyme Disease Awareness}


In regard to having general awareness about LD among hikers in British Columbia, $98 \%$ of the respondents had heard about the disease before this study and $74 \%$ of respondents think ticks are problematic for hikers. When asked "Do you know if Lyme Disease exist in BC?" Among all respondents, 83.1\% answered "yes" and are aware that LD exist in BC and $16 \%$ of them was not sure if the disease exists in BC.

\section{Preventive Measures}

Overwhelming majority, $92 \%$ of total respondents, were taken at least one preventive measure to avoid tick bite while hiking regardless of their level of awareness about LD. (Figure 3)

\section{Type and Frequency of Preventive}

\section{Measures}

1. Usage of Insect repellent

The usage of insect repellent to protect against tick bite which is the recommended and effective method by Centre for Disease Control (CDC 2020), was not the most frequent and popular choice among the population of this study. In fact, approximately $68 \%$ of respondents to this question "Usage frequency of insect repellants" never or rarely used insect repellent to avoid tick bites.
2. Body check after hiking

Similar to usage of insect repellents, body check and searching for tick was also unpopular among the study population. $60 \%$ of respondents to this question never or rarely did the checking for ticks after hiking.

3. Wearing protective cloths or Tucking pants into socks

These preventive methods were the least frequent methods taken by hikers. Among respondents to the question about frequency of wearing protective cloths, $47 \%$ of respondents never took such a method against ticks. And 54\% of respondents never tuck their pants into their socks to avoid ticks.

4. Using a preventive method other than the one in survey questions

Participants in the survey were asked if they take any preventive methods other than the one in the survey questions. From 112 respondents to this question, 20 people were answered "yes". This means $17 \%$ of all respondents takes some type of preventive measure other than the ones asked in the survey questions to avoid tick bites.

\section{Avoiding tall grasses and bushwalking}

The most frequent preventive measure among population in survey was assessed 
from respondents who took at least one preventive measure, 105 persons, and completed 5 related questions. The most frequent method was determined by the total score of each question. The Highest score was from "avoiding tall grasses and bushwalking" measure. It was observed that $46 \%$ of respondents frequently (more than half the time) chose to avoid tall grasses and bushwalking in their hikes.

\section{Inferential Statistics}

Chi-Square test was performed on NCSS software in order to do inferential statistical analysis. Chi-Square is a nonparametric test that designed and used to determine the associations between group differences when the dependent variables have nominal data (Mchugh, 2013).

Number of statistical tests were performed to explore possibility of associations related to knowledge and preventive behaviors among BC hikers. It was finally determined that Chi-Square test is the suitable test to compare two or more variable. Therefore, Pearson's Chi-Square test was performed for all 4 different hypotheses.

Table 1. explains the reasoning behind each hypothesis test performed as well as the result for each test in this study. 
Figure 1. Level of education of the respondents

\section{Level of Education}

$40.00 \%$

$35.00 \%$

$30.00 \%$

$25.00 \%$

$20.00 \%$

$15.00 \%$

$10.00 \%$

$5.00 \%$

$0.00 \%$
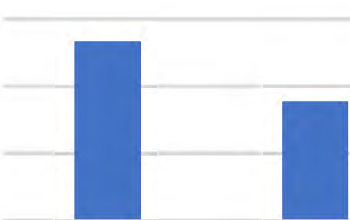

High school or Some college or

earlier grades technical school technical schoo
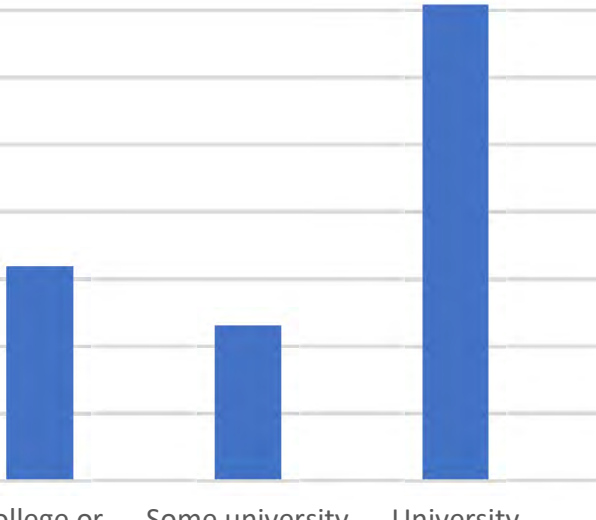

University undergraduate diploma

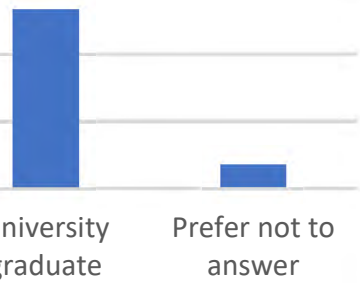

degree

Figure 2. Self-claimed level of hiking experience

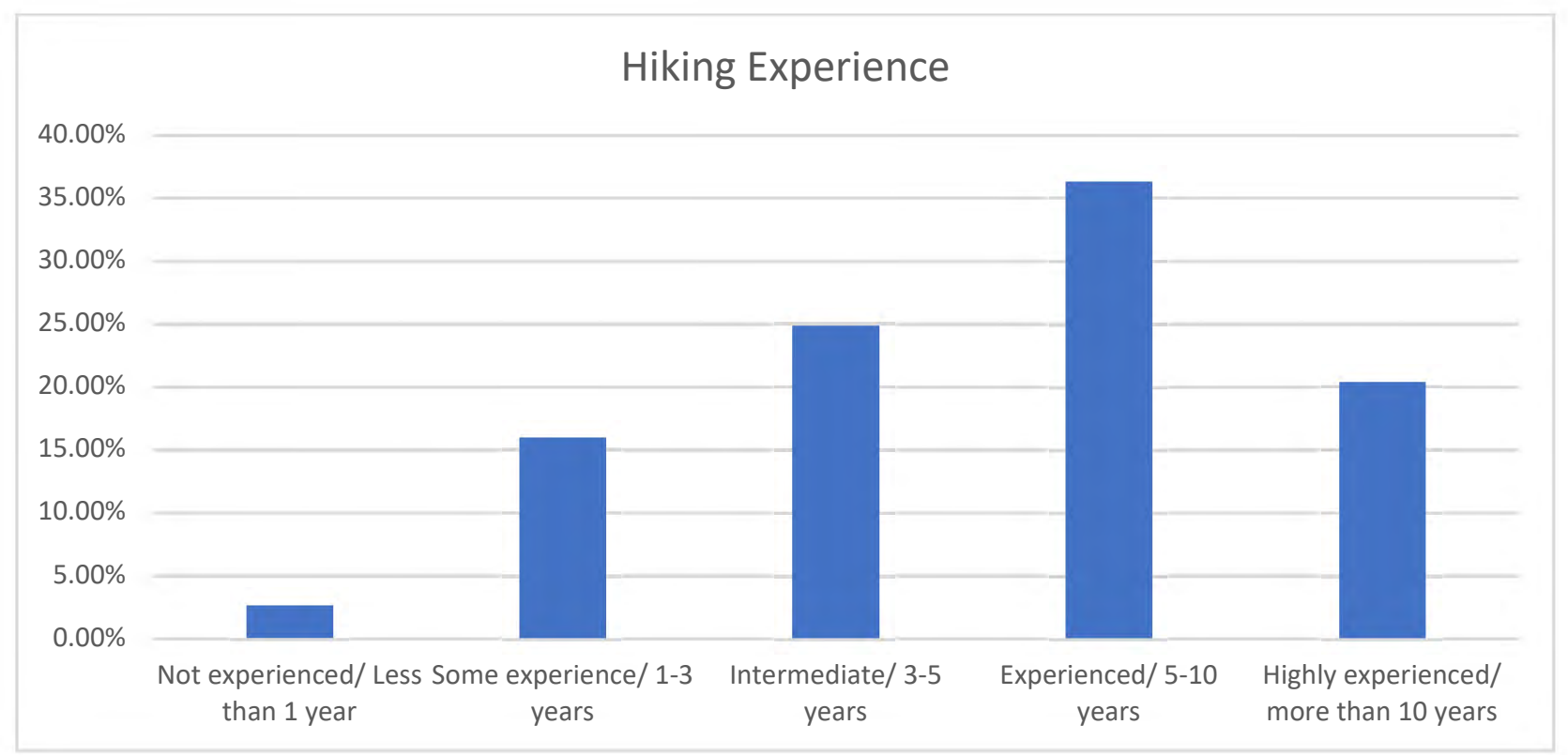


Figure 3. Lyme Disease Knowledge and Preventive measure

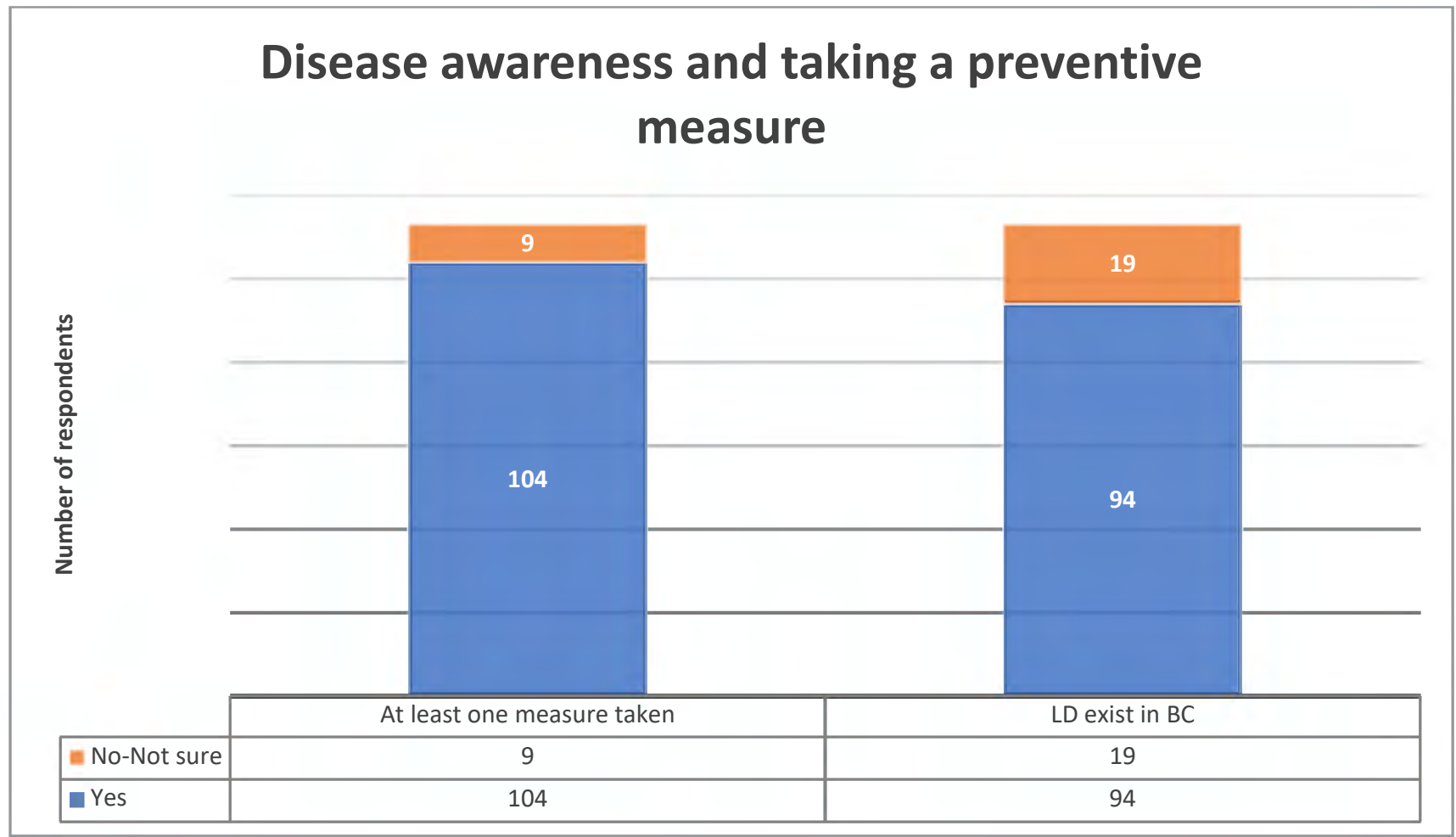


Table 1. Result of each test of hypothesis

\begin{tabular}{|c|c|c|c|}
\hline Hypothesis $\left(\mathrm{H}_{0}\right.$ and $\left.\mathrm{H}_{\mathrm{a}}\right)$ & Reasoning & $\mathrm{P}$ value & Interpretation \\
\hline $\begin{array}{l}\mathrm{H}_{0} \text { : There is NO } \\
\text { association between } \\
\text { hikers' knowledge about } \\
\mathrm{LD} \text { and their level of } \\
\text { education. } \\
\mathrm{H}_{\mathrm{a}} \text { : There is an association } \\
\text { between hikers' knowledge } \\
\text { about LD and their level of } \\
\text { education. }\end{array}$ & $\begin{array}{l}\text { If the hikers' } \\
\text { education level has } \\
\text { any meaningful } \\
\text { association with } \\
\text { their knowledge } \\
\text { level of Lyme } \\
\text { disease }\end{array}$ & 0.7723 & $\begin{array}{l}\text { Do not reject the null hypothesis and } \\
\text { conclude that there is no statistically } \\
\text { significant association between } \\
\text { hikers' knowledge about LD and } \\
\text { their level of education. } \\
\text { Possible errors: No alpha errors. } \\
\mathrm{P}=0.77 \text { shows that the result has } \\
\text { high confidence that null hypothesis } \\
\text { could not be rejected. }\end{array}$ \\
\hline $\begin{array}{l}\mathrm{H}_{0}: \text { There is NO } \\
\text { association between } \\
\text { hikers' level of experience } \\
\text { and the preventive } \\
\text { measure taken } \\
\mathrm{H}_{\mathrm{a}} \text { : There is an association } \\
\text { between hikers' level of } \\
\text { experience and if any } \\
\text { preventive measure taken }\end{array}$ & $\begin{array}{l}\text { If hiking } \\
\text { experience and } \\
\text { hiking frequency } \\
\text { influence the } \\
\text { preventive measure } \\
\text { taken by the hiker } \\
\text { towards tick bites }\end{array}$ & 0.86962864 & $\begin{array}{l}\text { Do not reject the null hypothesis and } \\
\text { conclude that there is no statistically } \\
\text { significant association between } \\
\text { hikers' level of experience and if any } \\
\text { preventive measure taken. } \\
\text { Possible errors: No alpha errors. } \\
\mathrm{P}=0.86 \text { shows that the result has } \\
\text { high confidence that null hypothesis } \\
\text { could not be rejected. }\end{array}$ \\
\hline $\begin{array}{l}\mathrm{H}_{0} \text { : There is NO } \\
\text { association between } \\
\text { hikers' level of education } \\
\text { and the preventive } \\
\text { measure taken } \\
\mathrm{H}_{\mathrm{a}} \text { : There is an association } \\
\text { between hikers' level of } \\
\text { education and the } \\
\text { preventive measure taken }\end{array}$ & $\begin{array}{l}\text { If level of } \\
\text { education } \\
\text { influences the } \\
\text { method of } \\
\text { preventive measure } \\
\text { taken }\end{array}$ & 0.9113 & $\begin{array}{l}\text { Do not reject the null hypothesis and } \\
\text { conclude that there is no statistically } \\
\text { significant association between } \\
\text { hikers' level of experience and if any } \\
\text { preventive measure taken. } \\
\text { Possible errors: No alpha errors. } \\
\mathrm{P}=0.91 \text { shows that the result has } \\
\text { high confidence that null hypothesis } \\
\text { could not be rejected }\end{array}$ \\
\hline $\begin{array}{l}\mathrm{H}_{0} \text { : There is NO } \\
\text { association between } \\
\text { hikers' gender and LD } \\
\text { preventive behavior } \\
\mathrm{H}_{\mathrm{a}} \text { : There is an association } \\
\text { between hikers' gender and } \\
\text { LD preventive behavior }\end{array}$ & $\begin{array}{l}\text { if one gender take } \\
\text { measure to protect } \\
\text { themselves against } \\
\text { the tick bite more } \\
\text { than/less than the } \\
\text { other genders }\end{array}$ & 0.0682 & $\begin{array}{l}\text { Do not reject the null hypothesis and } \\
\text { conclude that there is no statistically } \\
\text { significant association between } \\
\text { hikers' gender and preventive } \\
\text { behavior. } \\
\text { Possible Beta error: } \\
\mathrm{P}=0.068 \text { shows that there is a } \\
\text { possibility that beta error occurred } \\
\text { which means that the result has not } \\
\text { rejected a false null hypothesis and } \\
\text { there might be an association } \\
\text { between hiker's gender and their LD } \\
\text { preventive behavior. }\end{array}$ \\
\hline
\end{tabular}




\section{Discussion}

\section{Lyme Disease knowledge}

The result of this study indicates that general awareness of Lyme disease among hikers in British Columbia is high. Overwhelming majority of participants, 98\%, in the study have heard about the LD before the study was conducted. Data shows that hikers in $\mathrm{BC}$ are generally aware of prevalence of the disease and know that ticks, carriers of LD bacteria is problematic for hikers. However, some participants (26\%) had no knowledge about the existence of the disease in $\mathrm{BC}$ or did not know that ticks are problematic for them. This lack of knowledge may support the idea for better education among hikers regarding the risk of Lyme disease and presence of ticks in $\mathrm{BC}$.

The level of knowledge about the Lyme disease among $\mathrm{BC}$ hikers is in contrast with the study conducted among recreational outdoor users in two Canadian cities (St. Pierre et al., 2020). In the study authors concluded that the LD knowledge level of outdoor recreational users are low while in our study, data shows that $\mathrm{BC}$ hikers are generally aware of the disease and majority of them take some preventive measure to prevent Lyme disease infection. This contrast between two studies is perhaps because our study was focused on a specific type of outdoor activity, hiking, while study conducted by St. Pierre has a broader range in terms of outdoor users. It has included a variety of recreational outdoor users and not specifically hikers. In addition, our study only reflects a portion of outdoor activities that its population might be exposed to ticks and not all recreational outdoor activities such as hunting, mountain biking, camping and other activities.

\section{Preventive Behavior}

Hikers in BC are taking effective measure to protect themselves from the LD. Among the hikers who are aware of the LD, Majority of them (92\%) have taken at least one measure to protect themselves against the disease. Although the most effective method suggested to prevent tick bites is using insect repellants (CDC, 2020), avoiding tall grasses and bushwalking was the most popular method among BC hikers. In contrast, wearing protective cloths or tucking pants into socks were the least frequent methods taken by hikers. This result suggests that avoiding tick bites by avoiding ticks is preferred over the usage of chemical compounds, insect repellants, to prevent tick bites. The harmful effect of chemical insect repellants on human maybe the reason behind this behavior, however, more data is needed to come to such a conclusion.

In general, our study indicates that majority of $\mathrm{BC}$ hikers take preventive measures to protect themself against LD. 
However, more data points are needed to precisely determine if these findings are a true representative of all hikers across the province. It is important to know that only hikers with access to internet and using social media, Reddit users in case of our study, participated in this survey. Younger generations are much more active in social media platforms than older hiking population. Therefore, utilizing different means of collecting data may yield different results.

\section{Test of Associations}

Performing Chi-Square test of variables in this study revealed that there is no association $\quad(p=0.91)$ between level of education and if a preventive method taken by hikers. This result indicates that taking a preventive measure against tick bite among hikers in $\mathrm{BC}$ is not directly related to their education level. One test of variables also concluded that there is no association $(p=0.86)$ between level of hiking experience and if LD preventative measure taken by the hiker. This result shows that even hikers with no experience tend to take measures to protect themselves as much as highly experience hikers do.

Another association test explored that if hiker's knowledge about the LD is associated with their education level. Although the result shows that there is no association $(p=0.77)$ between the education level of the hikers and they knowledge about LD, more data points in this variable are needed that investigators could satisfactorily accept the finding.

The results from test of variables also found no associations $(\mathrm{p}=0.068)$ between gender and preventive method taken against the disease. However, $\mathrm{p}=0.068$ indicates that the possibility of an error (beta) exists. A beta error in this test would suggest that there might be an association between taking preventive measures against tick bites and gender among $\underline{B C}$ hikers.

\section{Limitations}

This study has some limitations. Poor responses and selection biases are involved in the online surveys (McPeake, 2014). Since the survey is electronic/online, self-administered, lack an interviewer and is time limited, predicting the number of survey participants hence the number of useful responses in advance is difficult. It is also assumed that the respondents are truly met the inclusion criteria of the study and evaluation is solely based upon honesty of participants.

Sample population bias is a limiting factor. Not all study subjects are accessible and available via online platforms (Jones et al., 2013). Although most young hikers have 
access to social media and are users of social media, that is somewhat different in older age category of subjects where they use conventional means of communications rather than online platforms. In the United States, $46 \%$ of young aged $18-29$, use reddit while only $7 \%$ of older adults, 51 and up, uses reddit (Lin, 2021). Access to older age category of participants is limited to those who only use social media platforms, such as Reddit (Reddit, 2021). Thus, sample population bias is a limitation in this study.

There were also some limitations on survey dissemination on reddit pages. Many subreddit and community-based pages did not accept survey links simply because they do have "no survey" policy. Most major subreddit pages accepted the link although there might not be true representative of whole population.

\section{Knowledge Translation}

Results of this study might help the public health authorities to design more effective awareness and prevention campaigns in order to control LD in hiking population. Public health initiatives design by health officials could be tailored towards hiking population utilizing information from this study such as the most popular preventive measures or the most frequent method taken among BC hikers.
Education towards prevention of Lyme disease must focus on methods that have the most effectiveness. While our study shows that the most popular/ the most frequent preventive method taken against tick bite is avoiding tall grasses and bush walking, other studies pointed on different methods such as protective clothes or other methods being the most popular methods. The significance of education in this area depends on the region and prevalence of the disease on that region.

Hiking groups can benefit from the study in order to educate their members. The result of this study can be used to design educating tools regarding tick preventive methods. Knowing the behavior of hikers helps to consider that what preventive method is more practical or what methods are more suitable for the region.

Our findings show that although the awareness of $\mathrm{BC}$ hikers about the LD is relatively high, it is necessary to educate hikers about the disease. Our findings show that around $8 \%$ of people in our study never took any measure against the disease and $25 \%$ of them do not think that ticks are problematic for hikers. And that, regardless of current condition of the disease, shows that there is a need for education among hikers and perhaps more so among other outdoor users in $\mathrm{BC}$. That being said, our study did not assess the level of knowledge required for hikers to ensure they are protected against tick bites and Lyme 
disease and what preventive method is the most effective method. Based on our findings, education initiatives could be introduced to increase awareness of tick problems in hiker's communities and about tick bites and diseases they can carry.

\section{Future Research}

The area of interest for future research are:

1. Attitude and behavior of hikers toward Lyme disease in Canadian provinces with high prevalent of the disease.

2. Hiker's knowledge about chemical insect repellent and their effectiveness for Lyme disease prevention.

3. Association between having pet and human tick bites which leads to Lyme disease among recreational outdoor users in Canada.

\section{Conclusion}

As Lyme disease has been recognized as a potentially increasing infectious disease in British Columbia, assessment of hiker's knowledge and preventive behavior towards Lyme disease through an online survey concluded that BC hikers have high level of awareness about the disease in the province. Overwhelming majority of $\mathrm{BC}$ hikers take at least one preventive measure while hiking to prevent tick bites. Interestingly, in contrast with recommendations for using insect repellant as the most effective method of tick bite prevention, majority of hikers in $\mathrm{BC}$ prefer not to use chemical insect repellants. Instead, physical prevention such as avoid walking near tall grasses, avoiding ticks, or avoid bushwalking are the most popular preventive methods. Our study found that there are no significant statistical associations between level of education, hiker's hiking experience or gender of hikers and preventive methods they take against the Lyme disease.

\section{Acknowledgement}

The authors would like to thank British Columbia Institute of Technology and Environmental Health Department for their support during this study.

\section{Competing Interest}

The authors declare that they have no competing interests. 


\section{References}

Aenishaenslin, C., Bouchard, C., Koffi, J. K., \& Ogden, N. H. (2017). Exposure and preventive behaviours toward ticks and Lyme disease in Canada: Results from a first national survey. Ticks and TickBorne Diseases, 8(1), 112-118. https://doi.org/10.1016/j.ttbdis.2016.10.0 06

Aenishaenslin, C., Michel, P., Ravel, A., Gern, L., Milord, F., Waaub, J. P., \& Bélanger, D. (2015). Factors associated with preventive behaviors regarding Lyme disease in Canada and Switzerland: A comparative study. BMC Public Health, 15(1), 1-10. https://doi.org/10.1186/s12889-015-15392

Aenishaenslin, C., Bouchard, C., Koffi, J. K., Pelcat, Y., \& Ogden, N. H. (2016). Evidence of rapid changes in Lyme disease awareness in Canada. Ticks and Tick-Borne Diseases, 7(6), 1067-1074. https://doi.org/10.1016/j.ttbdis.2016.09.0 07

BC Centre for Disease Control, 2020 Reportable Diseases Data Dashboard. http://www.bccdc.ca/healthprofessionals/data-reports/reportablediseases-data-dashboard

Brownstein, J. S., Holford, T. R., \& Fish, D. (2005). Effect of Climate Change on Lyme Disease Risk in North America. EcoHealth, 2(1), 38-46. https://doi.org/10.1007/s10393-004-0139$\mathrm{x}$

Center for Disease Control, 2020 CDC newsroom. https://www.cdc.gov/media/dpk/diseasesand-conditions/lyme-disease/index.html

Due C, Fox W, Medlock JM, Pietzsch M, Logan JG. Tick bite prevention and tick removal. BMJ. 2013 Dec 9;347:f7123. doi: 10.1136/bmj.f7123. PMID: 24324215 .

Gupta, S., Eggers, P., Arana, A., Kresse, B., Rios, K., Brown, L., Sampson, L., \& Kploanyi, M. (2018). Knowledge and preventive behaviors towards tick-borne diseases in
Delaware. Ticks and Tick-Borne

Diseases, 9(3), 615-622.

https://doi.org/10.1016/j.ttbdis.2018.01.0 06

Halperin JJ. Chronic Lyme disease: misconceptions and challenges for patient management. Infect Drug Resist. 2015 May 15;8:11928. doi: 10.2147/IDR.S66739. PMID: 26028977; PMCID: PMC4440423.

Health Canada, 2019. Lyme Disease Surveillance Data. https://www.canada.ca/en/publichealth/services/diseases/lymedisease/surveillance-lymedisease.html\#a3

Henry B, Roth D, Reilly R, MacDougall L, Mak S, Li M, Muhamad M. How big is the Lyme problem? Using novel methods to estimate the true number of Lyme disease cases in British Columbia residents from 1997 to 2008. Vector Borne Zoonotic Dis. $2011 \mathrm{Jul} ; 11(7): 863-8$. doi: 10.1089/vbz.2010.0142. Epub 2011 Mar 17. PMID: 21413887.

Jones, T. L., Baxter, M. A., \& Khanduja, V. (2013). A quick guide to survey research. Annals of the Royal College of Surgeons of England, 95(1), 5-7. https://doi.org/10.1308/003588413X1351 1609956372

Koffi, J., \& Gasmi, S. (2019). Surveillance for Lyme disease in Canada: 2009-2015. Online Journal of Public Health Informatics, 11(1), 194-199. https://doi.org/10.5210/ojphi.v11i1.9892

Lin, Y. (2021, January 14). 10 Reddit Statistics You Should Know in 2021 [Infographic]. Oberlo. https://www.oberlo.ca/blog/redditstatistics

Lindsay, L., Ogden, N., \& Schofield, S. (2015). Review of methods to prevent and reduce the risk of Lyme disease. Canada Communicable Disease Report, 41(6), 146-153. https://doi.org/10.14745/ccdr.v41i06a04

Lloyd VK, Hawkins RG. Under-Detection of Lyme Disease in Canada. Healthcare (Basel). 2018 Oct 15;6(4):125. doi: 10.3390/healthcare6040125. PMID: 30326576 ; PMCID: PMC6315539. 
McHugh, M. L. (2013). The Chi-square test of independence. Biochemia Medica, 143149. https://doi.org/10.11613/bm.2013.018

McPeake, J. (2014). Electronic surveys: how to maximise success : Nurse Researcher: Vol. 21, No. 3 (RCNi). Nurse Researcher.

Mead PS. Epidemiology of Lyme disease. Infect Dis Clin North Am. 2015 Jun;29(2):187210. doi: 10.1016/j.idc.2015.02.010. PMID: 25999219.

NCSS 2021 Statistical Software (2021). NCSS, LLC. Kaysville, Utah, USA, ncss.com/software/ncss.

Ogden, N. H., Lindsay, L. R., Morshed, M., Sockett, P. N., \& Artsob, H. (2009). The emergence of Lyme disease in Canada. Cmaj, 180(12), 1221-1224. https://doi.org/10.1503/cmaj.080148Profi le, D. (2009). Hiking Product Overview. April 1-7.

Public Health Agency of Canada. (2021, March 3). Surveillance of Lyme disease Canada.ca. Government of Canada. https:/www.canada.ca/en/publichealth/services/diseases/lymedisease/surveillance-lymedisease.html\#a1

Public Health Agency of Canada. (n.d.). Lyme disease surveillance report: Preliminary annual report 2018 - Canada.ca. Government of Canada. Retrieved February 8, 2021, from https://www.canada.ca/en/publichealth/services/publications/diseasesconditions/lyme-disease-surveillancereport-2018.html

Public Health Agency of Canada. (n.d.). Prevention of Lyme disease - Canada.ca. Government of Canada. Retrieved June 18,2015 , from https://www.canada.ca/en/publichealth/services/diseases/lymedisease/prevention-lyme-disease.html

Reddit. (2021, April 25). Reddit. https://www.reddit.com

St. Pierre, S. E., Gould, O. N., \& Lloyd, V. (2020). Knowledge and knowledge needs about Lyme disease among occupational and recreational users of the outdoors. International Journal of Environmental
Research and Public Health, 17(1).

https://doi.org/10.3390/ijerph17010355 